\title{
A retrospective analysis of latissimus dorsi-serratus anterior chimeric flap reconstruction in 47 patients with extensive lower extremity trauma
}

\author{
Ravi Kumar Mahajan, Krishnan Srinivasan, Abhiskek Bhamre, Mahipal Singh, Prakash Kumar, \\ Ankush Tambotra ${ }^{1}$ \\ Department of Plastic and Reconstructive Surgery, ${ }^{1}$ Amandeep Hospital and Clinics, GT Road, Model Town, Amritsar 143001 , \\ Punjab, India
}

Address for correspondence: Dr. Krishnan Srinivasan, Department of Plastic and reconstructive Surgery, Amandeep Hospital and Clinics, Gt Road, Model Town, Amritsar - 143 001, Punjab, India. E-mail: s.drkrish@gmail.com

\section{ABSTRACT}

Background: Many flaps have been described for reconstruction of lower extremity defects, including, Latissimus Dorsi, Rectus abdominis, Anterolateral thigh perforator flaps, each having advantages and disadvantages. The defect location, size and specific geometric pattern of defect influences the type of flap that can be used. In this case series, we describe the specific situations where the use of chimeric latissimus dorsi-serratus anterior (LD + SA) free flaps are of advantage in providing complete wound cover. Materials and Methods: Case records of all patients who underwent LD + SA free flap transfer for lower extremity trauma at Amandeep Hospital, from Feb 2006 to Feb 2017 were reviewed. Patients were categorised based on the anatomical location and size of defect. The method of usage of the chimeric segments, recipient vessels and type of anastomosis were noted. Flap complications, if any were reviewed. Result: 47 patients with lower limb defects were included in the study. All cases were post traumatic in nature. Defect size ranged from $180 \mathrm{sq} \mathrm{cm}$ to $1050 \mathrm{sq} \mathrm{cm}$. Average defect size was $487.70 \mathrm{sq} \mathrm{cm}$. All patients underwent soft tissue reconstruction with LD + SA flap. Complete wound cover was obtained. Conclusion: Latissimus dorsi + Serratus anterior free tissue transfer is an effective, reliable method of providing cover to extensive lower limb traumatic defects with minimal donor site morbidity, with added freedom of inset and flap positioning. Specific use is seen in patients with broad proximal defect, long defect in the leg, defects involving adjacent anatomical areas and in large defect with dead space.

\section{KEY WORDS}

Chimeric flap; latissimus dorsi; lower limb reconstruction; serratus anterior; trauma

\begin{tabular}{|l|l|}
\hline \multicolumn{2}{|c|}{ Access this article online } \\
\hline Quick Response Code: & Website: \\
\hline
\end{tabular}

This is an open access article distributed under the terms of the Creative Commons Attribution-NonCommercial-ShareAlike 3.0 License, which allows others to remix, tweak, and build upon the work non-commercially, as long as the author is credited and the new creations are licensed under the identical terms.

For reprints contact: reprints@medknow.com

How to cite this article: Mahajan RK, Srinivasan K, Bhamre A, Singh M, Kumar $P$, Tambotra A. A retrospective analysis of latissimus dorsi-serratus anterior chimeric flap reconstruction in 47 patients with extensive lower extremity trauma. Indian J Plast Surg 2018;51:24-32. 


\section{INTRODUCTION}

oad traffic accidents are a major cause of disability across the globe. It is estimated that two million people in India suffer from disability related to road traffic accidents(RTA). ${ }^{[1]}$ Most of these are in the productive age group of $15-44 . .^{[1]}$ Appropriate and complete wound cover for lower limb trauma and fracture form an important aspect which helps in recovery and rehabilitation of trauma patient.

Even with the advent of microvascular-free tissue transfer, management of extensive lower limb defects remains a challenge. Various fasciocutaneous and musculocutaneous flaps such as anterolateral thigh flap, ${ }^{[2]}$ latissimus dorsi (LD) muscle flap, gracilis muscle flap and rectus abdominis flap have been described for the management of lower extremity reconstruction. ${ }^{[3]}$ High-velocity trauma at times, produces lower limb defects which cannot be covered with any single flap alone, either due to the sheer size of defect or its geometrical alignment and anatomical location. Defects which are broad, especially at the proximal part, are difficult to be covered even by LD muscle alone as the proximal muscle part of the muscle is narrower.

Inability to provide complete cover could result in the need for amputation.

Although the use of subscapular system-based chimeric flaps has been described for lower extremity reconstruction, ${ }^{[3]}$ the number of cases in the series is limited.

We present a study of subscapular system-based combined LD+SA chimeric free tissue transfer for reconstruction of extensive defects of the lower limb, in a series of 47 patients. In this article, we highlight the specific anatomical features and geometrical arrangement of post-traumatic defects where the use of LD + SA chimeric flap would be of advantage over other flaps.

\section{MATERIALS AND METHODS}

This study was undertaken in conformity with the Declaration of Helsinki.

Case records of all patients who underwent $L D+S A$ free flap transfer for lower extremity reconstruction at Amandeep Hospital, Amritsar, from February 2006 to
February 2017 were reviewed. Patients were categorised based on the anatomical location of the defect and size of defect. The method of usage of the chimeric muscle segments, ischaemia time, recipient vessels and type of anastomosis were noted. Flap complications if any were reviewed.

The wound was divided based on anatomical location into - upper $1 / 3^{\text {rd }}$, middle $1 / 3^{\text {rd }}$ or lower $1 / 3^{\text {rd }}$ of leg, dorsum or sole of the foot or a combination of the above-mentioned anatomical areas. The maximum dimensions of the wound were measured with a sterile measuring tape. This was used to decide on the dimensions of the flap needed. The surface area was calculated by making a template of defect on a sterile lint cloth and superimposing it on a graph paper and the number of squares calculated.

Use of SA to fill the depth of the wound or to cover large defects was documented.

LD was harvested in the standard method described. Upper three slips of SA were left in place. Lower 4 slips were harvested based on the branch from the thoracodorsal artery.

Complications in terms of immediate partial or complete flap loss, need for re-exploration and delayed complications in the form of unstable scar, non-healing ulcers were documented.

Following flap cover and stabilisation of the flap, further fracture management was done by the orthopaedic team.

\section{Surgical procedure}

Pre-operative marking was made with the patient in sitting position ${ }^{[4]}$. The anterior border of LD was marked. Tip of the scapula and the midline of back were marked. Iliac crest was marked.

The side of harvest depended on the recipient vessel. In case of anastomosis to the anterior tibial pedicle, the same side muscle was chosen, and in case of posterior tibial pedicle, opposite side was chosen, as access to the recipient vessel was possible without change of position intraoperatively. The two-team approach was made. One team dissected the recipient vessels and also completed the debridement of wound, while the other team harvested the flap. Infiltration with adrenaline-saline solution was made (1 in 200,000) along the incision line. S-shaped 
incision along the anterior border of LD was made. Muscle was dissected from overlying subcutaneous tissue and from the underlying muscles. Thoracodorsal pedicle was dissected till the subscapular vessels. The branch to serratus anterior was preserved ${ }^{[5]}$. The point of entry of the SA branch of the thoracodorsal artery into the SA muscle was noted, and slips of SA, inferior to that are dissected off the medial border of the scapula and the underlying ribs [Figures 1 and 2]. ${ }^{|6|}$ Thus, upper three slips of SA were preserved and lower four slips harvested along with LD. During flap harvest, after raising the entire LD muscle, the distal perfusion is checked before dividing the flap. ${ }^{[4]}$

Once the recipient bed was ready, the flap was divided and anastomosis done using 9/0 nylon sutures. Donor site was closed in layers over suction drain. The flap was skin grafted on the $3^{\text {rd }}$ post-operative day.

\section{RESULTS}

A total of 47 patients with lower limb defects were included in the study. All cases were post-traumatic in nature, following road traffic accident. A total of 33 of them had right lower limb involvement and 14 had left lower limb involvement. The mean age of patients was 34.70, with age range of patients being from 7 to 62 years. Four patients were women and 43 were men.

Among the 47 patients, 43 were men and four were women. There was one patient in the $0-10$ years group, 7 in the 11-20 years group, 12 in 21-30 years, 12 in $31-40$ years, 8 in $41-50$ years, 3 in 51-60 years and 3 in $61-70$ years.

Among the total of 47 patients, 2 had defects involving knee and upper $1 / 3^{\text {rd }} ; 6$ had involvement of upper and middle $1 / 3^{\text {rd }}, 2$ had involvement of middle and lower $1 / 3^{\text {rd }}, 19$ had involvement of lower $1 / 3^{\text {rd }}$ and foot, out of which, six had involvement of heel pad and dorsum of foot, while 13 had only dorsum of foot involved. Nine patients had involvement of the foot and ankle, out of which, four had involvement of heel along with dorsum and five had involvement of dorsum and ankle region alone, sparing the heel. Six patients had the entire leg involved [Figure 3]. One patient had distal $1 / 3^{\text {rd }}$ involvement and partial amputation at that level. Two patients had involvement of middle $1 / 3^{\text {rd }}$ to foot involvement. Defect size ranged from $180 \mathrm{~cm}^{2}$ to 1050 $\mathrm{cm}^{2}$. Average defect size was $487.70 \mathrm{~cm}^{2}$ [Table 1].

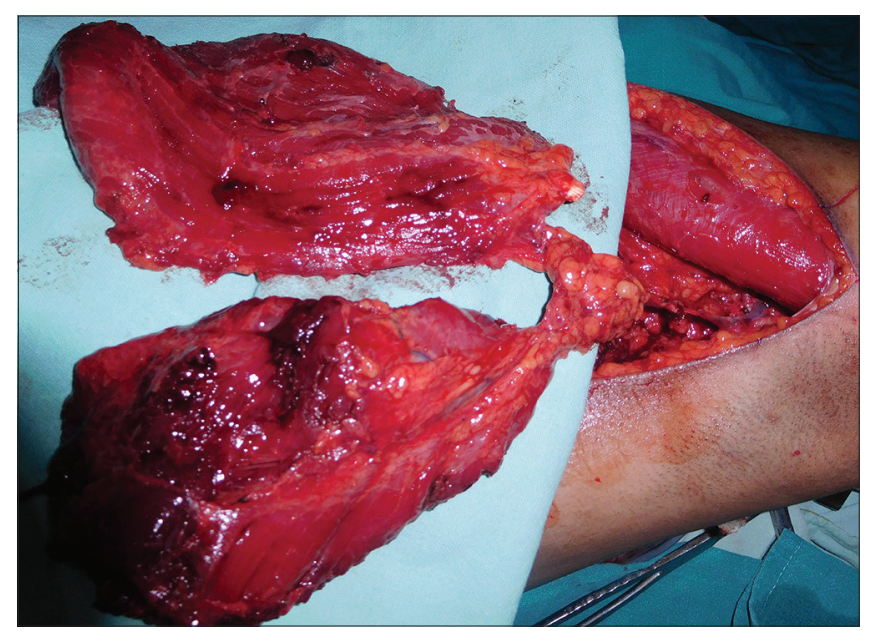

Figure 1: Latissimus dorsi + serratus anterior flap harvest - patient in lateral position. The common thoracodorsal pedicle is shown and the muscles have been completely dissected

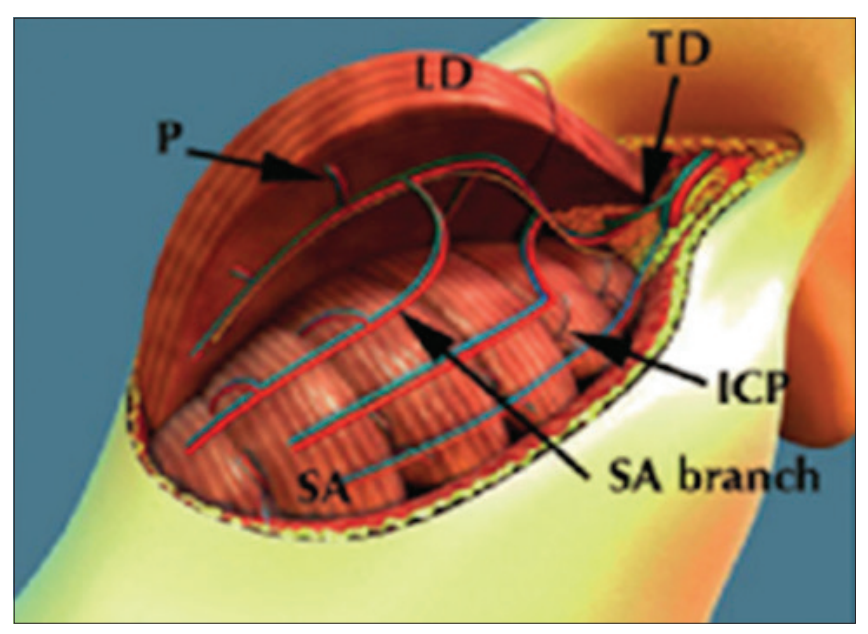

Figure 2: Preservation of upper 3 slips of serratus anterior by raising the flap below the point of entry of the vascular pedicle to serratus anterior

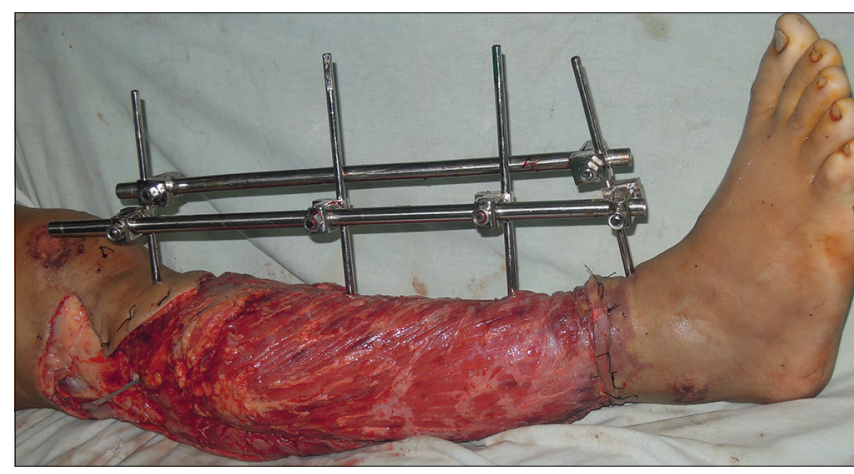

Figure 3: Defect involving the entire leg - covered by latissimus dorsi + serratus anterior flap over the bony part

Patient details are described in Table 2.

All patients underwent radical wound debridement and external fixation of the fracture (by orthopaedic team) initially, followed by LD + SA free tissue transfer within 
the next $72 \mathrm{~h}$. All patients underwent debridement as soon as possible and never later than $12 \mathrm{~h}$ after injury. Patients who underwent free flap on the $2^{\text {nd }}$ day after injury and debridement have been classified as being operated at $48 \mathrm{~h}$, and ones on the $3^{\text {rd }}$ day after injury as $72 \mathrm{~h}$. In our study, 43 patients underwent flap on day 2 ( $48 \mathrm{~h}$ ) following injury, 4 on the $3^{\text {rd }}$ day (72 h following injury).

Twenty-one patients had anastomosis done with the posterior tibial artery, 20 to the anterior tibial artery, 5 to the sural artery and 1 to lateral genicular artery. All anastomosis was performed end to end. The SA was used to fill the wound cavity in 10 patients and for large surface area in 37 patients.

One patient had complete flap necrosis which was managed with negative pressure wound therapy followed by cross-leg flap + skin graft of remaining raw area. Three flaps were re-explored due to venous congestion. Revision anastomosis was done and flap was salvaged. Partial flap necrosis was seen in two flaps which was managed with debridement and skin graft. Donor site morbidity - four patients had seroma formation which subsided with repeated aspirations. Five patients developed hypertrophic scar on the donor site suture line which was managed by triamcinolone injections and silicone gel sheet application.

Winging of the scapula was seen in one patient, though she did not have any complaints. Five patients, who had undergone resurfacing of foot defects, complained of flap being too bulky and underwent debulking procedure. One patient developed wound breakdown at the medial malleolar region at 2-year post-surgery. He was managed with dressings and skin graft.

\section{Case 1}

The case is an 18-year-old male with a history of RTA. There was a compound fracture in the tibia and patella

Table 1: Patient distribution according to the anatomical location of defect

\begin{tabular}{lc}
\hline Anatomical location of defect & Number of patients \\
\hline Knee + upper $1 / 3^{\text {rd }}$ & 2 \\
Upper + middle $1 / 3^{\text {rd }}$ & 6 \\
Middle + lower $1 / 3^{\text {rd }}$ & 2 \\
Lower $1 / 3^{\text {rd }}+$ ankle and foot & 19 \\
With heel involvement & 6 \\
Without heel involvement & 13 \\
Ankle + foot & 9 \\
With heel involvement & 4 \\
Without heel involvement & 5 \\
Entire leg & 6 \\
Other combination & 3 \\
\hline
\end{tabular}

with defect involving the knee and upper $1 / 3^{\text {rd }}$ of the right leg. Debridement and external fixator application were done [Figure $4 \mathrm{a}$ ]. On the $2^{\text {nd }}$ post-operative day, LD + SA free flap was done. Anastomosis was done to the lateral genicular artery, in a healthy plane posterior to the zone of trauma [Figure $4 \mathrm{~b}$ and $\mathrm{c}$ ]. The two muscles could be inset on either side of anastomosis, hence enabling complete wound cover [Figure 4d].

\section{Case 2}

The case was a 35-year-old male with the history of RTA. The defect involved part of the middle $1 / 3^{\text {rd }}$ and lower $1 / 3^{\text {rd }}$ of leg as well as ankle, dorsum of foot and heel [Figure 5a]. Muscles of deep posterior and part of anterior compartment were non-viable and were debrided, leaving a large defect needing filling of dead space around the bone. LD flap along with SA was harvested. SA was placed around the muscle in the depth of the wound [Figures 5b, $\mathrm{c}$ and $\mathrm{d}$ ].

\section{Case 3}

A 21-year-old female presented with a history of RTA. The left foot involved heel pad avulsion [Figure 6a]. Debridement + LDSA flap was done. SA was used to cover the heel and LD to cover the remaining raw area. Partial overlap of the two flaps at inset was present [Figure 6b, $c$ and $\mathrm{d}]$.

She developed winging of scapula. She did not have any shoulder weakness or complaints regarding day-to-day function.

\section{Case 4}

A 51-year-old male with a history of RTA sustained injury to the right leg with fracture tibia and degloving of skin over the leg. After debridement, he had a defect involving the upper $1 / 3^{\text {rd }}$ to lower $1 / 3^{\text {rd }}$ [Figure $7 \mathrm{a}$ ]. The defect was broad proximally. SA was used to cover the broad proximal aspect and LD the remaining part of the wound [Figure $7 \mathrm{~b}, \mathrm{c}$ and $\mathrm{d}$ ].

\section{DISCUSSION}

Extensive defects of lower extremities still have high rates of amputation because coverage of the defects is difficult even with largest conventional free flaps. ${ }^{[3]}$ Flaps that can be used for coverage of large lower limb defects with primary donor site closure are the LD muscle/myocutaneous flap, rectus abdominis ${ }^{[7]}$ muscle flap and occasionally even DIEP flap. ${ }^{[8]}$ Other options of coverage would be use of multiple flaps. 


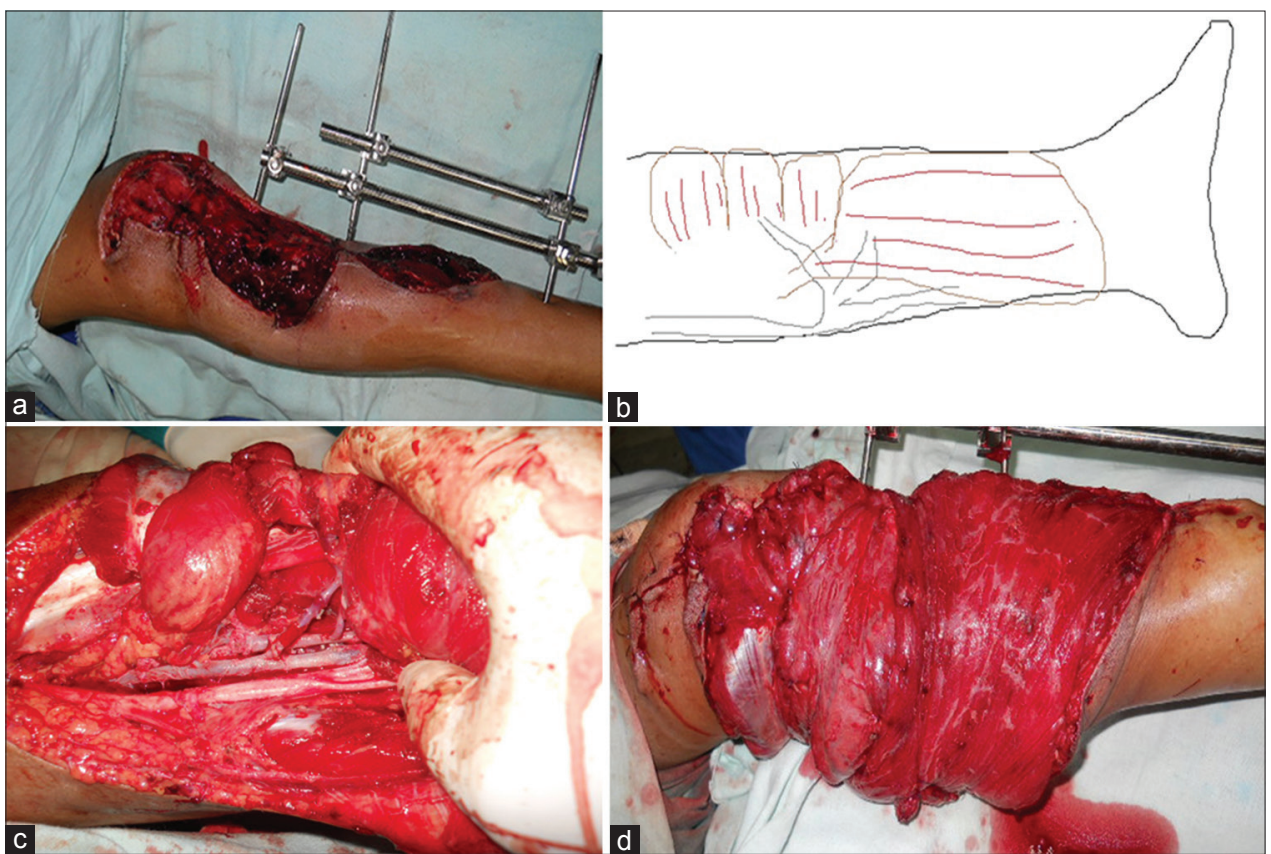

Figure 4: (a) Long defect involving upper and middle $1 / 3^{\text {rd }}$ of the leg. (b) Line diagram showing the anastomosis in a healthy zone posteriorly with the zone of trauma being in the anterior segment. Serratus anterior and latissimus dorsi are inset on either side of the anastomosis to provide complete wound

cover. (c) end-to-end anastomosis of thoracodorsal donor vessels to the lateral genicular recipient vessel posteriorly with anterior zone of trauma. Serratus anterior and latissimus dorsi are inset on either side of anastomosis. (d) Latissimus dorsi and serratus anterior inset on either sides of the anastomosis

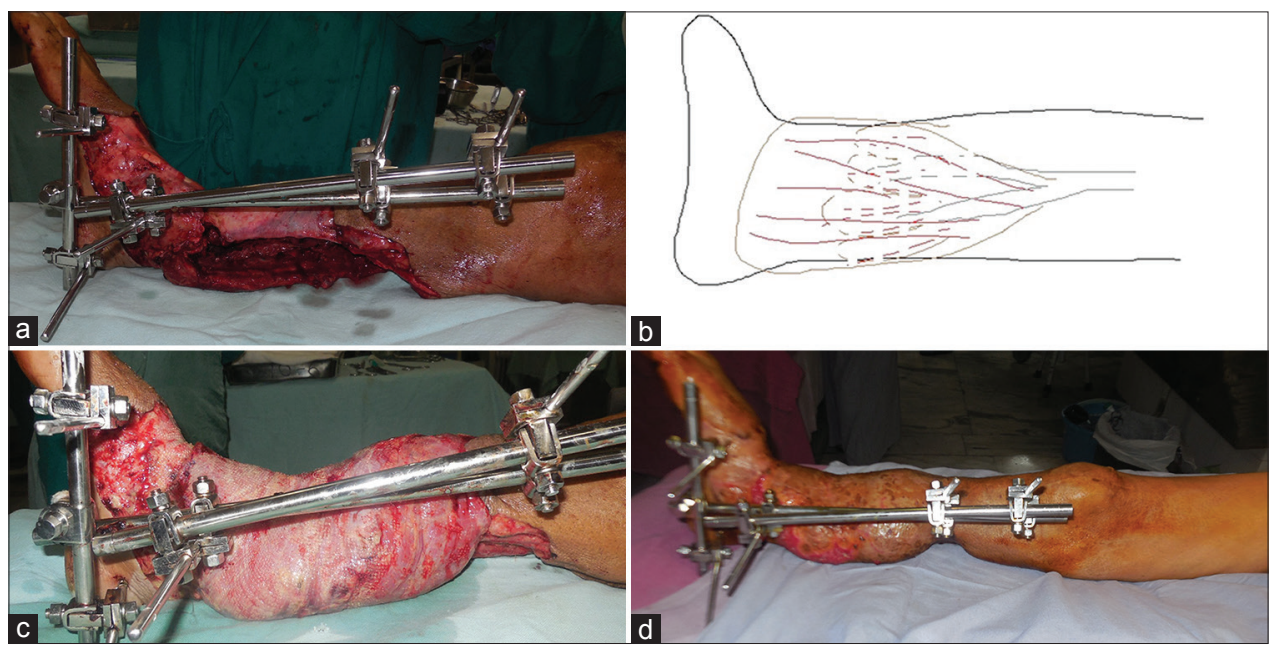

Figure 5: (a) Defect involving part of mid-lower $1 / 3^{\text {rd }}$ of leg and ankle. Wound cavity in the lower $1 / 3^{\text {rd }}$ of the leg around the tibia. (b) Line diagram showing serratus anterior used to fill in the dead space surrounding the bone and latissimus dorsi used to surface the remainder of defect. (c) Photograph of dead space at lower leg filled by serratus anterior and remainder resurfaced with latissimus dorsi flap. (d) Six-week follow-up

Anterolateral thigh flap with vastus lateralis muscle chimeric flap has been used by Wong et al. ${ }^{[2]}$ Use of large skin flap from ALT region necessitates skin graft and also use of large amount of vastus lateralis may cause weakness in knee extension. ${ }^{[3]}$

The use of conjoined flap, in the form of LD myocutaneous flap with parascapular flap, has been described for coverage of large defects. ${ }^{[9]}$ As the flaps share a common vascular pedicle in the form of subscapular artery, a single anastomosis was needed. As large area of skin is used as donor flap, skin grafting was needed in most patients to resurface donor defect. In contrast, when $L D+S A$ muscle flap is used, donor site can always be primarily closed.

Use of combined vertical rectus abdominis musculocutaneous (VRAM) and transverse rectus abdominis musculocutaneous flap has been described, as a case report, for coverage of extensive leg defect..$^{[10]}$ It has the advantage of being able to cover an extensive area. Donor site can also be closed primarily. There can be post-operative hernia development if the fascial layer is not meticulously 
Table 2: Patient details

\begin{tabular}{|c|c|c|c|c|c|c|c|}
\hline Age & Sex & Side & Site of involvement in leg & Recipient vessel & Anastomosis & Ischaemia time & Defect size $\left(\mathrm{cm}^{2}\right)$ \\
\hline 38 & Male & Right & $L+$ ankle $+D$ & $\mathrm{PT}$ & EE & $2 \mathrm{~h}$ & $180+D S$ \\
\hline 17 & Male & Left & $L+$ ankle $+D$ & AT & EE & $3 \mathrm{~h}$ & 800 \\
\hline 62 & Male & Right & $L+$ ankle $+D$ & AT & EE & $3 \mathrm{~h}$ & 225 \\
\hline 46 & Male & Right & $L+$ ankle $+D+P+$ Heel & PT & EE & $2.5 \mathrm{~h}$ & 1050 \\
\hline 38 & Male & Right & $L+$ ankle + D & PT & EE & $2.5 \mathrm{~h}$ & 900 \\
\hline 46 & Male & Left & $C+L$ & PT & EE & $2 \mathrm{~h}$ & 700 \\
\hline 32 & Male & Right & $U+C+L$ & SA & EE & $2.5 \mathrm{~h}$ & 770 \\
\hline 36 & Male & Left & Ankle + D & PT & EE & $3 \mathrm{~h}$ & 875 \\
\hline 27 & Male & Right & Ankle + heel pad + P & PT & EE & $3 \mathrm{~h}$ & 425 \\
\hline 52 & Male & Right & Ankle + D & PT & EE & $2 \mathrm{~h}$ & 500 \\
\hline 47 & Male & Left & $L+$ ankle + D & PT & EE & $2.5 \mathrm{~h}$ & 448 \\
\hline 26 & Female & Right & Knee $+U$ + popliteal & SA & EE & $3 \mathrm{~h}$ & $475+D S$ \\
\hline 28 & Male & Right & $U+C$ & SA & EE & $2.5 \mathrm{~h}$ & 450 \\
\hline 28 & Male & Left & $L+$ near total amputation & AT & EE & $2.5 \mathrm{~h}$ & $375+D S$ \\
\hline 18 & Male & Right & $U+C$ & SA & EE & $2.5 \mathrm{~h}$ & 420 \\
\hline 25 & Male & Right & $L+$ ankle $+D$ & PT & EE & $2 \mathrm{~h}$ & 625 \\
\hline 30 & Male & Left & $\mathrm{L}+$ ankle & PT & EE & $2 \mathrm{~h}$ & $600+D S$ \\
\hline 42 & Male & Right & $L+$ ankle $+P$ & PT & EE & $2.5 \mathrm{~h}$ & 400 \\
\hline 12 & Male & Right & Ankle + D & AT & EE & $2 \mathrm{~h}$ & 320 \\
\hline 32 & Male & Right & $L+$ ankle + D & AT & EE & $1 \mathrm{~h}$ & 384 \\
\hline 34 & Male & Left & $L+$ ankle + D & AT & EE & $2 \mathrm{~h}$ & $270+D S$ \\
\hline 13 & Male & Right & Ankle + D & AT & EE & $2 \mathrm{~h}$ & 400 \\
\hline 61 & Female & Right & $L+$ ankle $+D+$ heel & PT & EE & $1 \mathrm{~h}$ & 750 \\
\hline 30 & Male & Right & $U+C$ & AT & EE & $2 \mathrm{~h}$ & $300+D S$ \\
\hline 7 & Female & Left & $L+$ ankle + D & AT & EE & $2 \mathrm{~h}$ & 420 \\
\hline 14 & Male & Right & $L+$ ankle + D & AT & EE & $1 \mathrm{~h}$ & 360 \\
\hline 62 & Male & Right & $U+C$ & AT & EE & $2 \mathrm{~h}$ & 480 \\
\hline 52 & Male & Right & $\mathrm{C}+\mathrm{L}+$ ankle & AT & EE & $2 \mathrm{~h}$ & $486+D S$ \\
\hline 34 & Male & Right & $U+C$ & AT & EE & $2 \mathrm{~h}$ & $252+D S$ \\
\hline 28 & Male & Right & $\mathrm{L}+$ ankle & AT & EE & $2.5 \mathrm{~h}$ & 300 \\
\hline 45 & Male & Right & $U+C$ & SA & EE & $2 \mathrm{~h}$ & $270+D S$ \\
\hline 21 & Female & Left & Ankle + heel pad + P & PT & EE & $3 \mathrm{~h}$ & 375 \\
\hline 18 & Male & Right & $\mathrm{L}+$ ankle $+\mathrm{D}$ & PT & EE & $2 \mathrm{~h}$ & 420 \\
\hline 49 & Male & Right & $C+L+$ ankle & PT & EE & $2 \mathrm{~h}$ & 1050 \\
\hline 52 & Male & Left & $L+$ ankle $+D+$ heel pad & PT & EE & $3 \mathrm{~h}$ & 600 \\
\hline 60 & Male & Left & $L+$ ankle + D & AT & EE & $2 \mathrm{~h} 30 \mathrm{~min}$ & 286 \\
\hline 24 & Male & Right & Ankle + heel + P & AT & EE & $3 \mathrm{~h}$ & 375 \\
\hline 45 & Male & Left & $L+$ ankle $+D+$ heel & PT & EE & $2 \mathrm{~h}$ & 726 \\
\hline 25 & Male & Right & Ankle + D + P & PT & EE & $2 \mathrm{~h}$ & 500 \\
\hline 50 & Male & Right & Ankle + D & AT & EE & $2 \mathrm{~h}$ & $190+D S$ \\
\hline 32 & Male & Right & $\mathrm{U}$ to ankle $+\mathrm{D}$ & PT & EE & 1 and half & 276 \\
\hline 38 & Male & Right & Entire leg & AT & $E$ to $E$ & 2 & 456 \\
\hline 17 & Male & Left & $C+L$ & PT & EE & 1.5 & 264 \\
\hline 35 & Male & Right & knee and $U$ & $\begin{array}{l}\text { Lateral genicular } \\
\text { artery }\end{array}$ & EE & 2 & 392 \\
\hline 28 & Male & Right & $U+C+L+D$ & AT & EE & 2.5 & 960 \\
\hline 40 & Male & Right & $U+C+L$ & AT & EE & 1.5 & 512 \\
\hline 35 & Male & Right & $U+C+L$ & AT & EE & 2 & 330 \\
\hline
\end{tabular}

SA: Serratus anterior, PT: Posterior tibial, EE: End to end, AT: Anterior tibial; U - Upper 1/3rd of leg; C- middle 1/3rd of leg; L-lower1/3rd of leg; D-dorsum of foot; P-plantar aspect of foot; Desc genicular art- descending genicular artery. DS- Dead space

repaired. The patient can have difficulty in getting up from lying down position in the initial post-operative period. ${ }^{[11]}$ Hence, abdominal wall weakness due to loss of rectus abdominis muscle is a drawback of using VRAM flap.
In comparison, the disability (donor site morbidity) following combined harvest of LD and SA is minimal, as there are muscles which compensate for their loss. ${ }^{\mid 6,12]}$ 


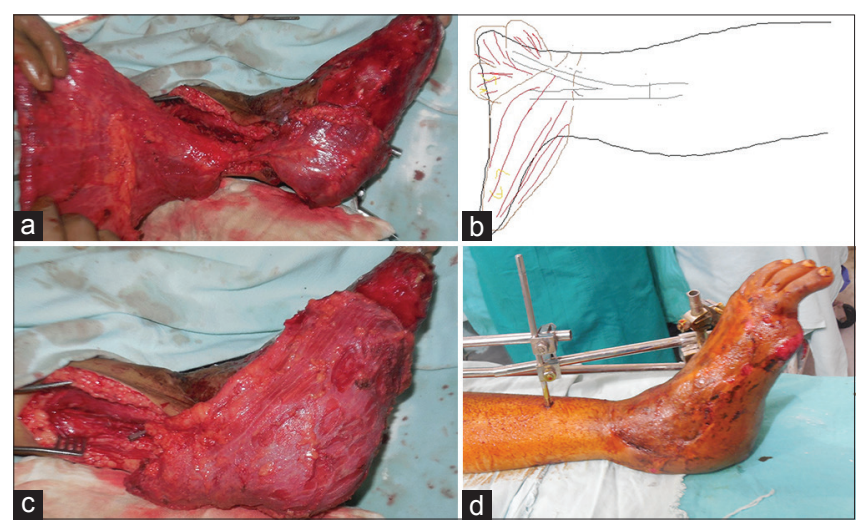

Figure 6: (a) Serratus anterior flap placed on the heel. (b) Line diagram showing use of serratus anterior to surface heel defect and latissimus dorsi for rest of the defect. (c) Heel defect covered by serratus anterior. Rest of the defect was covered by latissimus dorsi. Overlap of latissimus dorsi over serratus anterior was done during inset. (d) One-month post-operative picture

No significantly increased shoulder dysfunction in patients undergoing chimeric LD + SA. ${ }^{[3,13-15]}$ Even in our case series, we have found that only one patient had winging of scapula, and she did not have any functional disability or complaints either. Only on specific examination was the winging noticed. No other patient had winging or any other deformity related to LD + SA harvest. This finding corresponds with various other studies as referenced above.

Boomerang-extended rectus abdominis myocutaneous flap, described by Koul et al., is a large flap for coverage of extensive lower limb defects. It has been described as the longest possible flap for wound coverage as free flap. Its limitation being the ability to cover long, narrow defects and not broad defects. ${ }^{[16]}$ In comparison, the LD + SA flap can cover both long defects and wide ones.

Although DIEP provides a large volume of skin and fatty tissue, zone IV has classically been unreliable ${ }^{[3]}$ and redundant fat tissue makes the flap bulky and less useful for foot coverage $\mathrm{e}^{[3,8]}$

LD flap has a large surface area, is simple to harvest and its loss has minimal functional effect in an otherwise healthy patient. ${ }^{[4]}$ However, some trauma patients have defects too large for LD and also cavities created by bone and muscle loss that cannot be filled by LD alone.

Even though LD is a large muscle, it is at times difficult to use single muscle to cover an entire defect. Even if the size of the defect is same as LD muscle area, the location and shape of defect determine how the flap can be inset. The shape of LD muscle is such that it is narrower proximally, closer to its pedicle and broader as

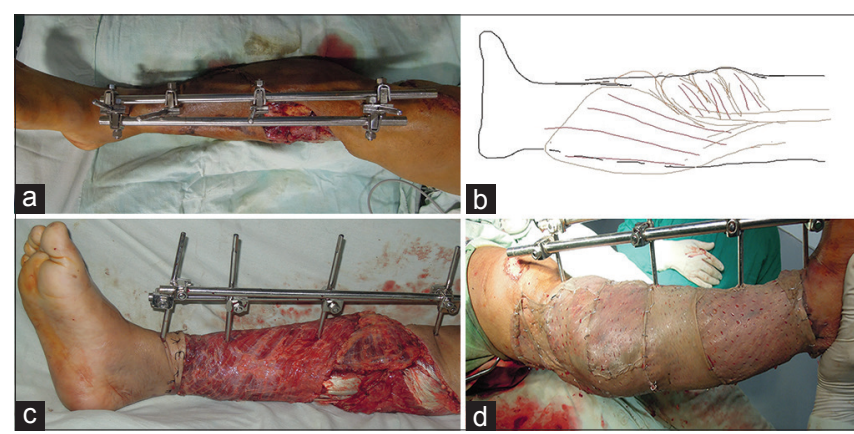

Figure 7: (a) Defect involving upper $1 / 3^{\text {rd }}$ with degloved non-viable skin till the ankle. Degloved skin was debrided. The defect is broad proximally. (b) Line diagram showing use of serratus anterior to cover broader proximal part of defect. (c) Picture showing serratus anterior covering broad proximal part and remainder covered by latissimus dorsi flap. (d) Flap skin grafted

it progresses distally. Hence, when LD is used to resurface defects in the leg which are broad proximally, the entire defect is not covered by LD. In such situations, the area left out is covered by SA muscle [Figure 7].

Use of chimeric LD + SA flap increases the surface area that can be covered. A chimeric flap is defined as a flap with 2 or more components with separate blood supply connected to a common pedicle. ${ }^{[17]}$ SA can be used to fill in cavitary defects, while LD can be used to surface large wound area [Figure 5], different anatomical locations in the lower limb can be covered by these two muscles [Figure 6]. In a long defect on the leg, anastomosis can be performed in a plane separate from the zone of trauma, in the middle of the defect, instead of going proximal to the defect itself. The two muscle components being on either side of anastomosis can provide complete wound coverage [Figure 4].

The pedicle involved is the same for both LD and SA being the thoracodorsal pedicle from the subscapular artery system. Single anastomosis is required, whereas double anastomosis would be required if two separate flaps were used or if supercharging was to be done in a large flap. By leaving behind upper 3 slips of the SA, winging of scapula is avoided ${ }^{[4]}$ and hence no donor site deficit occurs. Freedom of inset increases with the use of LD + SA flap as the two muscles can be inset independent of each other. ${ }^{[18]}$

Review of literature revealed few case series involving $\mathrm{LD}+\mathrm{SA}$ for lower limb reconstruction. Kim et al. reported a series of 12 patients with the use of thoracodorsal pedicle-based chimeric flaps, out of which SA was used in 3 patients, ${ }^{[3]}$ to fill dead space. 
Chimeric flaps based on the subscapular artery system have also been reported to be used in oral malignancy reconstruction, ${ }^{[13]}$ and thoracic cavity reconstruction following tumour resection ${ }^{[19]}$ using similar principle of filling dead space.

Use of combined LD + SA free flap for coverage of ankle defect has been described, with SA being used to fill the dead space and LD to cover the surface defect. ${ }^{[20]}$ Similar approach has been used by us in 10 defects having dead space.

We have found $L D+$ SA free flap to be a very useful tool in providing cover for extensive lower limb defects. LD is a type V muscle and SA type III. ${ }^{[21]}$ The chimeric flap is very reliable due to large calibre vessels and long pedicle. ${ }^{\mid 22]}$ The choice of recipient vessels depends on the location of defect, vascular status of the limb, status of the vessels, presence of backflow. ${ }^{[23]}$ In case of end-to-side anastomosis, posterior tibial artery is to be preferred. ${ }^{[24]}$ The arterial anastomosis can be performed either end-to-end or end-to-side to one of the main lower extremity vessels (anterior tibial or posterior tibial). ${ }^{[25]}$ All or vessel anastomosis were end-to-end.

The possible disadvantage is the bulk of the flap, especially in the ankle and dorsum of foot reconstruction. This can be troublesome in some patients and requires debulking at a later stage. Thinning is done by scraping off the skin graft, debulking and regrafting the flap. It is done if the patient desires the same due to excess bulk. Aesthetically, fasciocutaneous flap is better than muscle flap in the lower limb coverage. ${ }^{[25]}$

\section{CONCLUSION}

LD + SA free tissue transfer is an effective, reliable method of providing cover to extensive lower limb traumatic defects with minimal donor site morbidity, with added freedom of inset and flap positioning. The specific advantages of $L D+S A$ have been noted in patients having wide proximal defect and patients having dead space that needs to be filled apart from a large surface wound.

\section{Declaration of patient consent}

The authors certify that they have obtained all appropriate patient consent forms. In the form the patient(s) has/have given his/her/their consent for his/her/their images and other clinical information to be reported in the journal. The patients understand that their names and initials will not be published and due efforts will be made to conceal their identity, but anonymity cannot be guaranteed.

\section{Financial support and sponsorship}

Nil.

\section{Conflicts of interest}

There are no conflicts of interest.

\section{REFERENCES}

1. Gururaj G. Road traffic deaths, injuries and disabilities in India: Current scenario. Natl Med J India 2008;21:14-20.

2. Wong $\mathrm{CH}$, Ong YS, Wei FC. The anterolateral thigh - Vastus lateralis conjoint flap for complex defects of the lower limb. J Plast Reconstr Aesthet Surg 2012;65:235-9.

3. Kim SW, Youn S, Kim JD, Kim JT, Hwang KT, Kim YH, et al. Reconstruction of extensive lower limb defects with thoracodorsal axis chimeric flaps. Plast Reconstr Surg 2013;132:470-9.

4. Serafin $D$, editor. The latissimus dorsi muscle-musculocutaneous flap. Atlas of Microsurgical Tissue Transplantation. $1^{\text {st }}$ ed. United States of America: W.B. Saunders; 1996. p. 205-20.

5. Serafin D, editor. The serratus anterior muscle-musculocutaneous flap. In: Atlas of Microsurgical Tissue Transplantation. $1^{\text {st }}$ ed United States of America: W.B. Saunders; 1990. p. 191-204.

6. Collini FJ, Wood MB. The use of combined latissimus serratus free flap for soft tissue coverage in hand. Eur J Plast Surg 1989;12:179-82.

7. Musharafieh R, Macari G, Hayek S, Elhassan B, Atiyeh B. Rectus abdominis free-tissue transfer in lower extremity reconstruction: Review of 40 cases. J Reconstr Microsurg 2000;16:341-5.

8. Zeltzer AA, Van Landuyt K. Reconstruction of a massive lower limb soft-tissue defect by giant free DIEAP flap. J Plast Reconstr Aesthet Surg 2012;65:e42-5.

9. Hallock GG. The combined parascapular fasciocutaneous and latissimus dorsi muscle conjoined free flap. Plast Reconstr Surg 2008;121:101-7.

10. Chao AH, Coriddi M, Miller MJ. Reconstruction of extensive defects with combined transverse-vertical rectus abdominis (cruciate) myocutaneous flaps. Plast Reconstr Surg 2014;133:442e-3e.

11. Dinner MI, Labandter $\mathrm{H}$, Dowden RV. Rectus abdominis musculocutaneous flap. In: Strauch B, Vasconez L, Hall-Findlay EJ, Lee BT, editors. Grabb's Encyclopedia of Flaps. $1^{\text {st }}$ ed. Boston Toronto London: Little, Brown and Company; 1990. p. $1370-2$

12. Podrecca S, Tomic O, Salvatori P, Riggio E. Free composite osseomyocutaneous flap of latissimus dorsi, serratus anterior and rib for oromandibular recon. Eur J Plast Surg 2000;23:316-20.

13. Girod A, Nadaud F, Mosseri V, Jouffroy T, Rodriguez J. Use of chimeric subscapular artery system free flaps for soft-tissue reconstruction of the oral cavity and oropharynx: Advantages and donor-site morbidity. Plast Reconstr Surg 2009;124:445e-6e.

14. Harii K, Yamada A, Ishihara K, Miki Y, Itoh M. A free transfer of both latissimus dorsi and serratus anterior flaps with thorcodorsal vessel anastomosis. Plast Reconstr Surg 1982;70:620-9.

15. Takayanagi S, Ohtsuka M, Tsukie T. Use of the latissimus dorsi and the serratus anterior muscles as a combined flap. Ann Plast Surg 1988;20:333-9.

16. Koul AR, Nahar S, Prabhu J, Kale SM, Kumar PH. Free 
Boomerang-Shaped Extended Rectus Abdominis Myocutaneous flap: The longest possible skin/myocutaneous free flap for soft tissue reconstruction of extremities. Indian J Plast Surg 2011;44:396-404.

17. Hallock GG. The complete nomenclature for combined perforator flaps. Plast Reconstr Surg 2011;127:1720-9.

18. Rausky J, Binder JP, Mazouz-Dorval S, Hamou C, Revol M. Perforator-based chimaeric thoracodorsal flap for foot reconstruction. J Plast Reconstr Aesthet Surg 2013;66:1798-800.

19. Hussain ON, Sabbagh MD, Carlsen BT. Complex microsurgical reconstruction after tumor resection in the trunk and extremities. Clin Plast Surg 2017;44:299-311.

20. Kiyokawa K, Tanaka S, Kiduka Y, Inoue Y, Yamauchi T, Tai Y, et al. Reconstruction of the form and function of lateral malleolus and ankle joint. J Reconstr Microsurg 2005;21:371-6.
21. Mathes SJ, Hansen SL. Flap classification and its application. In: Mathes SJ, Hentz VR, editors. Plastic Surgery. $2^{\text {nd }}$ ed., Vol. 1. United States of America: Saunders; 2006. p. 373-5.

22. Germann G, Bickert B, Steinau HU, Wagner H, Sauerbier M. Versatility and reliability of combined flaps of the subscapular system. Plast Reconstr Surg 1999;103:1386-99.

23. Park S, Han SH, Lee TJ. Algorithm for recipient vessel selection in free tissue transfer to the lower extremity. Plast Reconstr Surg 1999;103:1937-48.

24. Karşıdağ S, Akçal A, Turgut G, Uğurlu K, Baş L. Lower extremity soft tissue reconstruction with free flap based on subscapular artery. Acta Orthop Traumatol Turc 2011;45:100-8.

25. Soltanian H, Garcia RM, Hollenbeck ST. Current concepts in lower extremity reconstruction. Plast Reconstr Surg 2015;136:815e-29e. 